\title{
Use of Teledermatology to Improve Dermatological Access in Rural Areas
}

Alberto Coustasse, $\operatorname{DrPH}, M D, M B A, M P H_{1}{ }^{1}$

Raghav Sarkar, MBBS, MPH, MS, ${ }^{2}$ Bukola Abodunde, $M H A_{1}{ }^{1}$

Brandon J. Metzger, MS, ${ }^{2}$ and Chelsea M. Slater, $M H A^{1}$

${ }^{7}$ Healthcare Administration Program, Lewis College of Business, Marshall University, South Charleston, West Virginia.

${ }^{2}$ Health Informatics Program, Marshall University, Huntington, West Virginia.

\section{Abstract}

Introduction: Dermatological access in rural regions has been impacted due to an acute, global dermatologist shortage coupled with a striking disparity in dermatologist density between urban and rural areas. As a result, the dermatological arena has been under notable pressure to amplify access. Teledermatology has entailed the use of technology to provide dermatological services to individuals located at a remote distance. The purpose of this literature review was to examine the effect of utilization of teledermatology to determine enhancement of dermatological access to residents of rural areas.

Materials and Methods: This review followed a systematic approach and utilized five electronic databases to obtain peerreviewed journal articles. A PRISMA approach was used and a total of 86 references were employed.

Results: Teledermatology programs have been able to complement conventional dermatological care to enhance dermatological access to rural areas that have suffered from a shortage of dermatologists and could aid in supplementing traditional care as well. Within rural settings, the results of three studies in this review indicated the importance of improved quality for diagnostic precision, whereas one study reported that clinical images might not provide sufficient insight to deliver clear-cut diagnoses. In addition, enhancements in diagnostic precision could be obtained by upgrades in phone cameras to capture images. Finally, to most of the existing literature, in using teledermatology, physician satisfaction has been stronger than patient satisfaction.

Conclusions: Teledermatology has had a beneficial impact in improving dermatological access to rural areas. The success of this technology is contingent upon the commitment and willingness of the dermatologist in utilizing it.
Keywords: access, quality of images, diagnostic accuracy, specificity, rural areas, teledermatology, telemedicine, e-health

\section{Introduction}

elemedicine has entailed the utilization of visual communication, data information, and interactive audio to effectuate the transfer of medical information, and to facilitate remote patient consultations, diagnosis, and treatment. ${ }^{1}$ Teledermatology has comprised the utilization of telemedicine and imaging to deliver remote dermatological services (clinical and laboratory) to patients located at a distance. ${ }^{2}$ It has been one of the most rapidly evolving branches of telemedicine ${ }^{3}$; in fact, dermatology has been one of the medical specialties where telemedicine has been most vigorously implemented. ${ }^{4}$ Lee and English reported that there are 229 dermatology-related mobile applications by 2013 and 98.3 out of 100 people had access to mobile cellular in 2015. ${ }^{5}$

The ever-increasing demand for specialized dermatological care coupled with the pressing need to boost patient access has placed considerable strain on dermatological services. ${ }^{6}$ Data about physician needs assessment have assessed that, for a maximum of 30,000 individuals, it should be at least one dermatologist available to provide necessary services. However, the current scenario has been far from ideal. ${ }^{7}$ The International Foundation for Dermatology has determined that $\sim 3$ billion individuals residing in 345 developing rural communities have suffered from inadequate dermatological care. ${ }^{7}$ Countries in the developing part of the world have been facing an alarming shortage in specialists like dermatologists. ${ }^{8}$

From a global perspective, about $38 \%$ of nations have integrated teledermatology programs, and only $30 \%$ have had entire government-funded agencies that have allocated financial support to develop further, adopt, and maintain this innovation. Teledermatology implementation in high-income nations has faced obstacles relating to restricted reimbursement for those specialists and issues related to patient privacy/ confidentiality, whereas in low-income countries, a shortage of technical skills and resource limitations have been grassroots hindrances to tele-establishment. ${ }^{9}$

The stark disproportion in physician density between urban and rural areas has been a concerning issue, with greater 
physician concentration in urban areas. ${ }^{10}$ Even though 54\% of the global population has been situated in urban areas with greater access to health resources than rural areas, a significant portion has still populated rural areas with little access. ${ }^{11}$ In these rural areas, time-sensitive, quality care has often been deficient, which has invariably resulted in a decline in patient health state. ${ }^{12}$ According to the U.S. Census Bureau's designation of urban and rural areas, urban areas denote densely developed territory and include residential, commercial, and other nonresidential urban lands (areas with more than 50,000 individual and groups with 2,500 to 50,000 people), whereas rural areas comprise all housing, population, and territory not included within an urban area. ${ }^{13}$ Urban regions in Canada and the United States have had a higher density of dermatologists than rural areas. ${ }^{14}$ In the United States, even though the number of dermatologists has increased from 1.9 to 3.2 for every 100,000 individuals from 1970 to 2010, there has been a shortage, with urban areas having a higher density (25 per 100,000 individuals) compared to numerous rural western and central counties that do not have access to any local dermatologist. $^{9}$

Given these multiple issues, teledermatologists have thought that delivering dermatological care through teledermatology could aid in improving access to inhabitants based in rural areas since its benefits could be extrapolated and mobilized to provide vital services remotely to individuals. ${ }^{15}$ Most of the teledermatology studies have been associated with diagnostic and treatment concordance and accuracy of this modality of treatment versus traditional care provided by a dermatologist in a face-to-face visit. The key metrics of concordance have included sensitivity and specificity, whereas accuracy has been determined by histopathological findings, as the gold standard. ${ }^{16}$ In addition, teledermatology could potentially ameliorate the national shortage and urban-rural disparity by cost-effective consultations and guidance for primary care physicians. $^{17}$ As an example, teledermatological models have been explored as a possible means of alleviating the restricted access and reduced costs to dermatologists in Australia. ${ }^{18}$ Moreover, a practical aspect of teledermatology has been that it has had a profoundly visual facet intrinsic in its function, ${ }^{19,20}$ which has also been inherent within the overall context of telemedicine. ${ }^{21}$ This know-how has caused novel opportunities for employing teledermatology in resourcestricken areas. $^{22}$
The purpose of this literature review was to examine the effect of utilization of teledermatology to determine enhancement of dermatological access to residents of rural areas.

\section{Methods}

The methodology design for this study was a literature review based on the research framework adapted from Yao et al. ${ }^{23}$ This research framework illustrates the process of utilizing teledermatology involves the needs of teledermatology in rural areas followed by the adoption and application; when the benefits and barriers were evaluated and settled out, the cycle continues (Fig. 1). This research framework was appropriate to this study as both the adopted and the original research frameworks used it for the adoption of technology. Its utilization in prior studies has supported the internal validity of this research framework. ${ }^{24-26}$

The methodology used in this review was a systematic review approach, and it was performed in three different stages: (1) Literature Identification and data collection; (2) Establishment of Inclusion Criteria and Literature analysis; (3) and Literature Categorization.

\section{STAGE 1: LITERATURE IDENTIFICATION AND COLLECTION}

The electronic databases of PubMed, EBSCOhost, Academic Search Premier, ProQuest, and Google Scholar databases were employed to obtain peer-reviewed literature. The following keywords were utilized in conducting the literature search: "teledermatology" OR "eHealth" OR "mHealth" AND "biopsy," OR “clinical images," OR “diagnostic test accuracy," OR "specificity" OR "patient/physician satisfaction" AND "rural consultation OR rural access" OR "real-time."

Following a PRISMA approach, citations and abstracts identified by the search were assessed to identify relevant articles. The search identified 225 relevant citations and articles

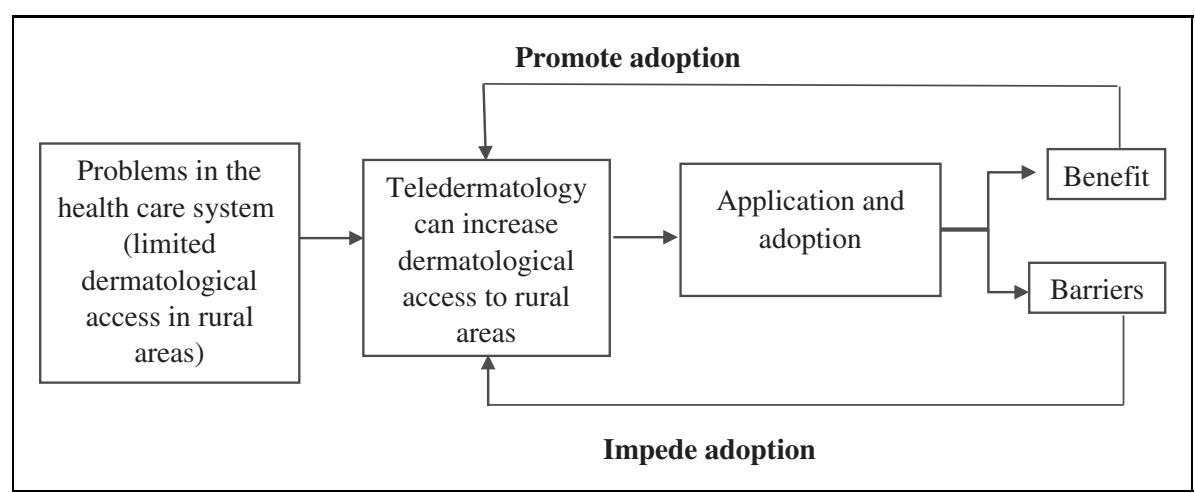

FIG. 1. Conceptual framework for the adoption of teledermatology to enhance dermatological access to rural areas. Source: Adapted from Yao et al. ${ }^{23}$ 


\section{COUSTASSE ET AL.}

were excluded ( $n=115)$ if they did not meet the inclusion criteria. In addition, articles were added $(n=86)$ if they identified teledermatological clinical outcomes (including diagnostic accuracy, patient satisfaction, and identification of skin malignancy) and/o teledermatological economic and/or access outcomes (including a reduction in travel time, waiting time, and consultation time). These 110 articles were subject to fulltext review; of these, 24 were excluded because they did not meet focus specifically on Teledermatology and rural health. At the conclusion of the full-text review, a total of 86 articles were included in the data abstraction and analysis (Fig. 2). ${ }^{27}$

\section{STAGE 2: ESTABLISHMENT OF INCLUSION CRITERIA AND LITERATURE ANALYSIS}

The literature examined was selected after a review of the abstracts was performed. Examined references were published in English, in rural settings and in between 2007 and 2018 to keep this review current. This evaluation scrutinized 86 references that were either conducted in rural settings (which could have also included remote environments distant from the nearest clinic, underserved areas, developing countries, or resource-stricken regions) or provided information concerning the viability of teledermatology in enhancing rural dermatological access.

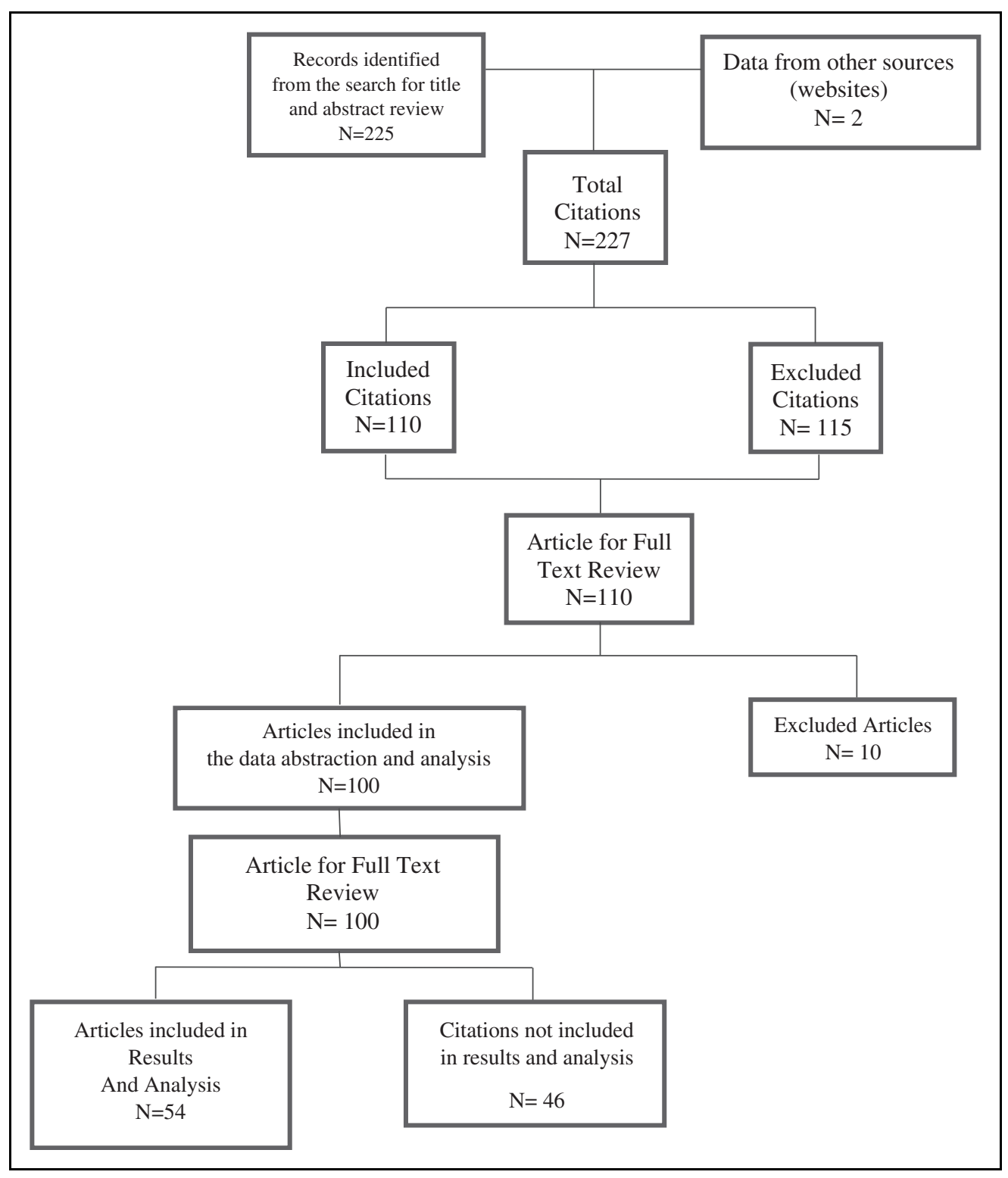

FIG. 2. Overview of literature evaluation following PRISMA Approach. Source: Moher et al. ${ }^{27}$

\section{STAGE 3: LITERATURE CATEGORIZATION}

The results that emerged from the systematic literature were classified as follows: diagnostic acuity and quality of images; waiting period for initial consultations, duration of consultations, and travel reduction; biopsy, identification of skin malignancy, referrals, and follow-up; and patient/physician satisfaction with the above four categories.

\section{Results}

DIAGNOSTIC ACUITY OF TELEDERMATOLOGICAL MODELS ALONG WITH QUALITY OF CLINICAL IMAGES ANALYZED

A systematic review conducted within the context of Australia's native population reported the teledermatological diagnostic accuracy of $80 \%$; it also revealed that accuracy rose from 66\% with poor-quality images to $87 \%$ with images of adequate quality. $^{28}$ Concordance levels between primary care practitioners and teledermatologists have been between $41 \%$ and $89 \%,{ }^{29}$ while it was $48 \%$ in another study. ${ }^{30}$ Thind et al. reported a study in which there was a 47\% diagnostic 
agreement between the dermatologist and the general practitioner with the utilization of teledermatology in the remote training of general practitioners in Burkina Faso. ${ }^{31}$ A 75\% diagnostic concordance level has been detailed in the study of Rubegni et al. ${ }^{32}$

Based on the levels of specialist referral concordance, diagnostic concordance, and management concordance, a Chilean research team concluded that $40.8 \%$ of consultations would be unnecessary by store-and-forward technology. ${ }^{33}$ Results from a randomized controlled trial conducted in a rural primary health care facility in Batangas, Philippines, did not find mobile teledermatology inferior to face-to-face consultations regarding clinical outcomes. ${ }^{34} \mathrm{~A}$ study conducted in a remote area in Egypt revealed 81.3\% complete concordance and 97\% partial/complete concordance rates, indicating that the cost-effective teleservice could enable educational programs and monitoring of practitioners. ${ }^{35}$ Within a nonrural context, a prospective study conducted in underserved, urban primary facilities in Philadelphia revealed that teledermatology could enhance outpatient care access and clinical results in these facilities by resolving diagnostic disagreements between primary care practitioners and dermatologists. ${ }^{36}$

For the dermatologist, clinical images of good quality have enhanced diagnostic precision. ${ }^{37}$ In addition to increased training of health care personnel, enhancements in diagnostic precision could be obtained by upgrades in phone cameras to capture images. $^{38}$ In one study, in addition to patient histories, teledermatologists accepted images with pixel ranging between $640 \times 480$ and $4,000 \times 3,000$ as sufficient image resolutions for diagnoses. $^{39}$ Analyzing clinical images has been a crucial component of diagnoses, and one study concluded that image quality was good enough to perform diagnoses using teledermatology, and it helped 75\% patients in their treatment. ${ }^{40}$

However, Tsang and Kovarik's study concluded that clinical images may not deliver adequate information to provide a definitive diagnosis and that microscopic examination of specimens was vital in providing accurate diagnoses, as well as in recommending appropriate treatment options. ${ }^{41}$ Moreover, a systematic review of 78 studies conducted that in a nonrural context, two-thirds of studies indicated enhanced diagnostic accuracy with clinic dermatology as opposed to teledermatology. Also, the authors concluded that teledermatology and teledermatoscopy were not as accurate as clinic dermatology in evaluating malignant lesions. ${ }^{42}$ A direct observational study in a nonrural setting inferred that the percentage of management and diagnostic concordance between in-person examination, liveinteractive technology, and store-and-forward technology was high; however, the study posited that dermatologists relied more on in-person examinations than on the other two telemodalities of treatment. ${ }^{43}$
The previous studies that were conducted within a rural context have been further detailed in Table 1, including a research that reported 28\% and 36\% concordance rates of treatment recommendations, while other studies described varying concordance rates between 58\% and 97\%. These studies concluded that teledermatology was viable in augmenting rural access (Table 1).

\section{WAITING PERIOD, DURATION OF CONSULTATIONS, AND TRAVEL REDUCTION}

A systematic review performed within a rural context reported that the waiting period for an initial teledermatological consultation extended anywhere between 4.6 to $71 \mathrm{~h}$ and 58 min-this has been in sharp contrast to the average 90-day waiting period in the United States for a face-to-face appointment. ${ }^{27}$ A report that gathered information about the Veterans Integrated Services Network also revealed reduced waiting time with the technology. ${ }^{44}$ In rural provinces of Nova Scotia, Canada, in 2009, it was reported that teledermatological videoconferencing appointments decreased the scheduled waiting time duration from 13.7 weeks for face-to-face appointments to 4.6 weeks. ${ }^{45}$ However, regarding consultation durations, a Viber-based mobile teledermatological setup in rural Nepal reported that direct consultations took $5 \mathrm{~min}$, whereas teleconsultations took $12 \mathrm{~min} .{ }^{46}$ A randomized cluster trial evaluated this technique using a mobile phone platform in rural Mongolian clinics and it has obtained promising results: a reduction of $19,892 \mathrm{~km}$ in travel distance and $269 \mathrm{~h}$ in travel time was noted, along with a $\$ 76.36$ per-patient decrease in expenses and a 75\% reduction in referrals to tertiary centers. ${ }^{47}$

Comparable results were obtained in studies that were conducted within a nonrural context. It has reported waiting periods of 2 to 50 days with the teledermatology system, compared to 88 to 137 days with the conventional letter referral. $^{48}$ Another analytical study showed that teledermatology reduced the waiting times from 26.5 to 9 days compared to face-to-face diagnosis. ${ }^{49}$ Wootton et al.'s systematic review also reported a dearth of studies concerning travel reduction. That study's analysis of 20 literature articles revealed that in 12 studies, an average value of $43 \%$ in travel reduction was possible with the utilization of teledermatology, and in the remaining eight studies, 70\% of patients were not required to travel for care. ${ }^{50}$

\section{BIOPSY, IDENTIFICATION OF SKIN MALIGNANCY, REFERRALS, AND FOLLOW-UP OF TELEDERMATOLOGY PROJECT}

Only one 2015 study about biopsies performed with teledermatological models was obtained. Within the Veterans 


\section{Table 1. Selected Studies About Diagnostic Acuity and Quality of Clinical Images in Rural (Including Remote, Indigent, and Developing Country) Settings}

\begin{tabular}{|c|c|c|c|}
\hline AUTHORS & SETTING OF STUDY & OUTCOME & CONCLUSION \\
\hline Chen et al. ${ }^{30}$ & $\begin{array}{l}\text { A descriptive retrospective cohort study of the elec- } \\
\text { tronic medical records of } 429 \text { pediatric patients was } \\
\text { performed to assess treatment regimen patterns; these } \\
\text { patients were referred from rural primary facilities in } \\
\text { California (utilizing store-and-forward technology) to a } \\
\text { teledermatology practice based in the San Francisco } \\
\text { Bay area. }\end{array}$ & $\begin{array}{l}28 \% \text { of treatment recommendations were } \\
\text { concordant, } 36 \% \text { were partially concordant, } \\
\text { and } 36 \% \text { were not concordant; } 1.4 \% \text { and } \\
6.0 \% \text { of patients had to undergo additional } \\
\text { teleconsultations and in-person consulta- } \\
\text { tions, respectively. }\end{array}$ & $\begin{array}{l}\text { The study concluded that teletech- } \\
\text { nology improved diagnostic and } \\
\text { treatment care for pediatric } \\
\text { patients who had inadequate access } \\
\text { to dermatologists. }\end{array}$ \\
\hline Garcia-Romero et al. ${ }^{40}$ & $\begin{array}{l}\text { A pilot teledermatological study involved a public social } \\
\text { networking website, in which the general practitioner at } \\
\text { a rural clinic would transmit clinical images of } \\
\text { dermatological conditions-through Facebook-to } \\
\text { dermatologists at a reference hospital. One of the } \\
\text { parameters evaluated was image quality in the website } \\
\text { to formulate diagnoses. }\end{array}$ & $\begin{array}{l}75 \% \text { of patients benefitted from diagnoses } \\
\text { and appropriate treatment. }\end{array}$ & $\begin{array}{l}\text { Teleservice through a website has } \\
\text { been used for delivering care to } \\
\text { individuals who lack access. }\end{array}$ \\
\hline Muir et al. ${ }^{39}$ & $\begin{array}{l}\text { In this pilot study in Queensland, Australia, the } \\
\text { feasibility of utilizing a store-and-forward Skin Emer- } \\
\text { gency Telemedicine Service to quickly deliver specialist } \\
\text { dermatological care for emergency department patients } \\
\text { was evaluated for } 60 \text { participants. }\end{array}$ & $\begin{array}{l}\text { The utilization of the technology revealed a } \\
96 \% \text { clinical management concordance rate } \\
\text { between telediagnosis and the emergency } \\
\text { department diagnosis (with 4\% relative } \\
\text { agreement). }\end{array}$ & $\begin{array}{l}\text { The technology could deliver } \\
\text { specialist care to rural areas. }\end{array}$ \\
\hline Rubegni et al. ${ }^{32}$ & $\begin{array}{l}\text { The therapeutic agreement, diagnostic agreement, and } \\
\text { degree of diagnostic confidence of the store-and- } \\
\text { forward teledermatological system were compared with } \\
\text { face-to-face consultations by examining } 130 \text { geriatric } \\
\text { patients in this direct observational study in Siena, Italy. }\end{array}$ & $\begin{array}{l}\text { The therapeutic agreement between both } \\
\text { methods was } 69.6 \% \text { (Cohen's } K=0.640 \text { ), and } \\
\text { the diagnostic agreement (yielding the same } \\
\text { ICD- } 9 \text { code) was } 87.7 \% \text { (Cohen's } K=0.863 \text { ); } \\
\text { however, dermatologists displayed uncer- } \\
\text { tainty on diagnoses provided by telemedicine. }\end{array}$ & $\begin{array}{l}\text { The system could augment diag- } \\
\text { nostic and therapeutic care for } \\
\text { geriatric patients who have suffered } \\
\text { from a lack of access. }\end{array}$ \\
\hline Tran et al. ${ }^{38}$ & $\begin{array}{l}\text { In this feasibility study in Cairo, Egypt, diagnostic } \\
\text { concordance rates for } 30 \text { patients were evaluated by } \\
\text { face-to-face consultations and by a } 5 \text {-megapixel } \\
\text { camera attached to a software-based mobile telephone. }\end{array}$ & $\begin{array}{l}\text { An overall } 75 \% \text { mean diagnostic agreement } \\
\text { rate between face-to-face consultations } \\
\text { and teleconsultations was obtained. }\end{array}$ & $\begin{array}{l}\text { Mobile teledermatology could be a } \\
\text { reliable means of delivering care to } \\
\text { impoverished areas. }\end{array}$ \\
\hline Tsang and Kovarik ${ }^{41}$ & $\begin{array}{l}\text { A retrospective case review about the African Tele- } \\
\text { dermatology Project involved the submission of biopsy } \\
\text { specimens to centers in the United States for definitive } \\
\text { clinical diagnoses. }\end{array}$ & $\begin{array}{l}\text { A 58\% clinic-pathological concordance rate } \\
\text { between the diagnosis of the submitting } \\
\text { physician in remote areas of Africa and the } \\
\text { definitive biopsy results in the United States } \\
\text { was obtained. }\end{array}$ & $\begin{array}{l}\text { Dermatopathology could aid in } \\
\text { diagnosing and treating dermato- } \\
\text { logical conditions in developing } \\
\text { countries. }\end{array}$ \\
\hline Thind et al. ${ }^{31}$ & $\begin{array}{l}\text { In this feasibility study in Aberdeen, United Kingdom, a } \\
\text { teledermatology system was implemented to boost } \\
\text { supervision of rural general practitioner training in } \\
\text { dermatology, and to examine concordance rates be- } \\
\text { tween consultant diagnoses and general practitioner } \\
\text { with particular interest (GPwSI) diagnoses (with the aid } \\
\text { of teledermatology) for } 230 \text { selected referrals. }\end{array}$ & $\begin{array}{l}\text { Store-and-forward teledermatology } \\
\text { demonstrated a } 61 \% \text { diagnostic } \\
\text { concordance rate. }\end{array}$ & $\begin{array}{l}\text { The study reported that telederma- } \\
\text { tology could complement inade- } \\
\text { quate dermatological care in } \\
\text { remote areas. }\end{array}$ \\
\hline Gatica et al. ${ }^{33}$ & $\begin{array}{l}\text { In this direct observational study, a teledermatology } \\
\text { electronic platform of the Ministry of Health was } \\
\text { evaluated for } 125 \text { patients to gauge the ability in } \\
\text { eliciting dermatological diagnoses for primary care } \\
\text { patients in rural health centers in Chile. }\end{array}$ & $\begin{array}{l}\text { There was an } 82.4 \% \text { agreement percentage } \\
\text { between diagnoses elicited by the onsite } \\
\text { dermatologist and the teledermatologists. } \\
\text { The treatment concordance and specialist } \\
\text { referral concordance were } 75.2 \% \text { and } \\
73.6 \% \text {, respectively. }\end{array}$ & $\begin{array}{l}\text { Teledermatology could enhance } \\
\text { access to care in isolated areas. }\end{array}$ \\
\hline Byrom et al. ${ }^{37}$ & $\begin{array}{l}\text { A retrospective case analysis evaluated Tele-Derm, a } \\
\text { teledermatological initiative that has delivered derma- } \\
\text { tological advice to dermatologists who have provided } \\
\text { clinical care to rural populations of Australia. }\end{array}$ & $\begin{array}{l}\text { Among the } 83 \% \text { of cases that clinical } \\
\text { images were provided for, } 73 \% \text { were } \\
\text { determined to be of good quality. }\end{array}$ & $\begin{array}{l}\text { The technology has delivered } \\
\text { precise diagnoses and treatment } \\
\text { resulting in patient outcomes } \\
\text { comparable to face-to-face } \\
\text { sessions. }\end{array}$ \\
\hline
\end{tabular}




\begin{tabular}{|c|c|c|c|}
\hline AUTHORS & SETTING OF STUDY & OUTCOME & CONCLUSION \\
\hline Carpio et al. ${ }^{34}$ & $\begin{array}{l}\text { A randomized controlled trial was conducted in a rural } \\
\text { health center in Batangas, Philippines. The study } \\
\text { compared clinical efficacies of mobile phone teleder- } \\
\text { matology (mdermatology) utilized by a general practi- } \\
\text { tioner (GP) with that of face-to-face visits with a } \\
\text { dermatologist. }\end{array}$ & $\begin{array}{l}\text { The level of diagnostic concordance differed } \\
\text { between general practitioners and derma- } \\
\text { tologists; however, concordance in man- } \\
\text { agement was comparable. }\end{array}$ & $\begin{array}{l}\text { The utilization of the mdermatology } \\
\text { application has potential in a rural } \\
\text { primary health care facility, free } \\
\text { clinic setup. }\end{array}$ \\
\hline Cutler et al. ${ }^{29}$ & A feasibility study was conducted in rural Haiti. & $\begin{array}{l}\text { A concordance rate of } 75.09 \% \text { in diagnostic } \\
\text { acuity was achieved between primary care } \\
\text { practitioners and teledermatologists. }\end{array}$ & $\begin{array}{l}\text { Teledermatology has been a means } \\
\text { of delivering care to rural residents. }\end{array}$ \\
\hline Saleh et al. ${ }^{35}$ & $\begin{array}{l}\text { An analytical study was conducted in a remote area of } \\
\text { Egypt to assess the telesystem by determining diag- } \\
\text { nostic concordance rates between face-to-face der- } \\
\text { matologists and teledermatologists. }\end{array}$ & $\begin{array}{l}\text { The rates between one face-to-face der- } \\
\text { matologist and two teledermatologists were } \\
86.7 \% \text { and } 87 \% \text {, respectively. }\end{array}$ & $\begin{array}{l}\text { The study could facilitate teleutili- } \\
\text { zation in remote areas. }\end{array}$ \\
\hline Finnane et al. ${ }^{49}$ & $\begin{array}{l}\text { An analytical study was conducted on the accuracy of } \\
\text { skin cancer diagnosis compared between face-to-face } \\
\text { diagnosis and teledermatology. }\end{array}$ & $\begin{array}{l}\text { The diagnostic accuracy rate for face-to- } \\
\text { face is } 67-85 \% \text {, which is higher than } \\
\text { teledermatology with a rate of } 51-85 \% \text {. }\end{array}$ & $\begin{array}{l}\text { The time saving was a significant } \\
\text { benefit when utilizing telederma- } \\
\text { tology, especially in rural areas. }\end{array}$ \\
\hline
\end{tabular}

Affairs Corporate Data Warehouse, Vedire et al.'s retrospective chart review compared teledermatology-directed surgical complication rates delivered by primary care providers at rural clinics with rates performed by specialists by conventional surgery. ${ }^{51}$ The study reported a $2.0 \%$ biopsy and a $7.7 \%$ wide-local excision complication at rural clinics, and a 2.5\% biopsy complication rate and a 13.5\% wide-local excision complication rate in severely dysplastic nevi by specialist conventional surgery. ${ }^{51}$

Only one 2014 study about the identification of skin malignancies with teledermatological models in rural areas of the United States was obtained. Karavan et al.'s retrospective chart review involved the Veterans Integrated Service Network 20 (in the Pacific Northwest region of the United States) that delivered teleservices to 27 rural community-based outreach clinics. $^{52}$ The researcher found that $180(40 \%)$ melanoma cases (identified by face-to-face consultations) resided in regions where the teleservice was offered, suggesting that the higher incidence of melanoma in the face-to-face group was primarily due to inadequate use of the technology. Moreover, the study posited that in regions where the teleservice was employed, it identified a more significant number of advanced melanoma cases that had a severe, initial prognosis. ${ }^{51}$

Literature about referrals and general follow-up in rural settings have been limited. A 2008 chart review study, performed in three remote primary care clinics in the United States, revealed that when compared to conventional referrals, teledermatology referrals reduced the average duration for the initial consultation, biopsy, and surgery by 44,19 , and
21 days, respectively. ${ }^{53}$ In addition, Kahn et al. compared the time duration to biopsy utilizing teledermatology referrals with the time duration to biopsy using conventional dermatology referrals to dermatological clinics. It was revealed that the average time to biopsy of skin cancer was 9.7 days with teledermatology referrals and 13.8 days with traditional referrals, suggesting that with enhanced triaging measures, the utilization of teledermatology in remote areas shortened the time to biopsy. ${ }^{54}$

After implementing a follow-up protocol and tracking system that evaluated an established teledermatology project in rural areas of the U.S. Pacific Northwest, 93 conditions (out of 1,454 conditions requiring clinic pathological correlation consultations) were met with revisions in final diagnoses. The importance of the protocol was illustrated by the fact that the follow-up of the teledermatology project was vital in assuring enhancement of patient health outcomes. ${ }^{55}$

\section{PATIENT/PHYSICIAN SATISFACTION OF TELEDERMATOLOGICAL MODELS}

Studies describing physician and patient satisfaction along with physician education in rural areas were also obtained. A systematic review implemented within a rural context reported that, according to most of the existing literature, in using teledermatology, physician satisfaction has been stronger than patient satisfaction. ${ }^{26}$ Unexpectedly, there has been a deficiency of studies regarding physician satisfaction, with even fewer investigations regarding imaging technician satisfaction. ${ }^{56}$ 


\section{COUSTASSE ET AL.}

\begin{tabular}{|c|c|c|c|}
\hline Vallejos et al. ${ }^{57}$ & $\begin{array}{l}\text { An exploratory study was conducted in eastern North } \\
\text { Carolina rural clinics, in which dermatologists provided } 79 \\
\text { consultations to farmworkers utilizing store-and-forward } \\
\text { teledermatology. }\end{array}$ & $\begin{array}{l}12 \% \text { of consultations were rated as "some- } \\
\text { what helpful," and the rest were rated as } \\
\text { "helpful" or "very helpful." }\end{array}$ & $\begin{array}{l}\text { The study indicated that teleconsul- } \\
\text { tations could be a valuable tool for } \\
\text { farmworkers. }\end{array}$ \\
\hline Hsueh et al. ${ }^{62}$ & $\begin{array}{l}\text { A Veterans Integrated Service Network } 20 \text { Rural Telederma- } \\
\text { tology Quality Improvement Project was conducted in the } \\
\text { Pacific Northwest (Idaho, Alaska, Washington, and Oregon) } \\
\text { to assess patient satisfaction with both the teleservice and } \\
\text { with face-to-face consultations in rural clinics. }\end{array}$ & $\begin{array}{l}66 \% \text { of patients favored teledermatology } \\
\text { over face-to-face appointments, and } 83 \% \\
\text { of patients would have recommended the } \\
\text { teleservice to other veterans. }\end{array}$ & $\begin{array}{l}\text { Most rural patients had favorable } \\
\text { views toward the technology. }\end{array}$ \\
\hline McFarland et al. ${ }^{56}$ & $\begin{array}{l}\text { A store-and-forward teledermatology project was con- } \\
\text { ducted in underserved, rural regions of the Pacific } \\
\text { Northwest (Idaho, Alaska, Washington, and Oregon) to } \\
\text { deliver care to veterans; moreover, continuing education } \\
\text { sessions for rural primary care providers were established } \\
\text { and assessed by } 20 \text { multiple-choice questions on the } \\
\text { "Basic-20" quiz. }\end{array}$ & $\begin{array}{l}\text { Providers amplified their knowledge of skin } \\
\text { conditions on the quiz from } 63 \% \text { correct at } \\
\text { baseline to } 74 \% \text { accurate at the end of } 1 \\
\text { year; moreover, } 83 \% \text { of providers and } 92 \% \\
\text { of imaging technicians indicated that these } \\
\text { sessions were useful. }\end{array}$ & $\begin{array}{l}\text { The educational aspect of the } \\
\text { teleproject provided enhanced skills } \\
\text { to providers and imaging techni- } \\
\text { cians, thereby augmenting access } \\
\text { to underserved areas. }\end{array}$ \\
\hline Assis et al. ${ }^{60}$ & $\begin{array}{l}\text { A retrospective study was conducted in Minas Gerais, } \\
\text { Brazil, to evaluate teleconsultations performed with the } \\
\text { Telehealth Network of Minas Gerais (TNMG), which has } \\
\text { been a service that has assisted primary care physicians. }\end{array}$ & $\begin{array}{l}\text { 97\% of primary care practitioners were } \\
\text { satisfied with the TNMG. }\end{array}$ & $\begin{array}{l}\text { The TNMG has been a practical tool } \\
\text { to provide dermatological care to } \\
\text { remote and isolated areas. }\end{array}$ \\
\hline Biscak et al. ${ }^{59}$ & $\begin{array}{l}\text { A pilot study employing a clinical questionnaire was } \\
\text { conducted in remote areas of Queensland, Australia. }\end{array}$ & $\begin{array}{l}100 \% \text { of clinicians found the state-wide } \\
\text { store-and-forward teledermatology service } \\
\text { to be beneficial, and } 97 \% \text { of clinicians } \\
\text { reported that they would utilize it again, } \\
\text { with one clinician stating "possibly" on the } \\
\text { questionnaire. }\end{array}$ & $\begin{array}{l}\text { Teledermatology could have a sig- } \\
\text { nificant role in delivering health } \\
\text { care to remote areas in Australia. }\end{array}$ \\
\hline McFarland et al. ${ }^{58}$ & $\begin{array}{l}\text { A Veterans Integrated Service Network } 20 \text { Rural Tele- } \\
\text { dermatology Quality Improvement Project was executed in } \\
\text { rural veteran's administration clinics in the Pacific North- } \\
\text { west (Idaho, Alaska, Washington, and Oregon) to deter- } \\
\text { mine provider and imaging technician satisfaction rates. }\end{array}$ & $\begin{array}{l}71 \% \text { of primary care providers and } 94 \% \text { of } \\
\text { imaging technicians were satisfied or very } \\
\text { satisfied with the project; moreover, } 95 \% \text { of } \\
\text { providers also believed that tele-education } \\
\text { programs on diagnosis and treatment were } \\
\text { beneficial. }\end{array}$ & $\begin{array}{l}\text { The Veterans Health Administra- } \\
\text { tion's program could spur similar } \\
\text { teledermatology programs in rural } \\
\text { areas. }\end{array}$ \\
\hline
\end{tabular}

In another analysis, results have indicated that $86 \%$ of providers rated the consultations as helpful or very helpful with the technology and had perceived teleconsultations as an educational tool ${ }^{57}$ After participating in educational sessions, providers could conduct dermatological procedures and formulate diagnoses. ${ }^{58}$ One study reported an overwhelmingly positive response from clinicians. ${ }^{59}$ High physician satisfaction rates of $97 \%$ have reinforced the utility of teledermatology in providing care to isolated cities and remote areas that have encountered acute dermatologist shortages. ${ }^{60}$

In addition, a direct observational study revealed favorable patient views in the ability of teledermatology to limit expenses, decrease travel time, and facilitate shorter waiting periods. ${ }^{61}$ According to Hsueh et al., perceptions of adequate care and follow-up and obtaining educational information were associated with a higher patient satisfaction rate of $78 \% .{ }^{62}$ All the above six studies conducted in rural settings have illustrated high patient and/or physician satisfaction, and have been further detailed in Table 2.

\section{Discussion}

The purpose of this research project was to examine the effect of utilization of teledermatology to determine enhancement of dermatological access to residents of rural areas. Results of the literature review have suggested that teledermatology could increase dermatological access to underserved, rural areas. 
Teledermatology programs have been able to complement conventional dermatological care to enhance dermatological access to rural areas that have suffered from a shortage of dermatologists, ${ }^{63}$ and could aid in supplementing traditional care as well. ${ }^{64}$ Also, this technology could assist if incorporated into a regional dermatological service. ${ }^{65}$ The technology could permit rural patients to capture images as a complimentary evaluation tool to augment clinical care, ${ }^{66}$ while urban-based dermatologists could refine or enhance rural general practitioner diagnoses. ${ }^{67}$ Other studies have revealed that the technology could substitute for conventional care; moreover, pilot studies have indicated that diagnostic sensitivity and specificity could be within satisfactory ranges of traditional care. ${ }^{68}$ This review posits that it could be highly improbable for teledermatology to mitigate the necessity for conventional care, while still ensuring equivalent patient safety and quality of care levels.

It has generally been accepted that the diagnostic accuracy of teledermatology has been lower compared with face-toface consultations. ${ }^{69,70}$ Concerning diagnostic acuity in rural settings, this review has reported varying fluctuations in diagnostic concordance rates. This review stated that all images utilized in formulating diagnoses for rural patients could be relayed to an urban center for confirmation; even though this would inevitably prolong the consultation process and involve additional fees for the rural patient, the likelihood of a precise diagnosis could be enhanced.

Greater diagnostic precision has depended on the enhanced quality of clinical images observed. ${ }^{71,72}$ Within rural settings, results of three studies in this review indicated the importance of improved quality for diagnostic precision, whereas one study reported that clinical images might not provide sufficient insight to deliver clear-cut diagnoses. The central tenet of teledermatology has revolved around image clarity, and higher degrees of accuracy would undoubtedly assist in identifying the correct diagnosis. However, this review suggested that sole reliance on even high-quality images as a confirmatory diagnostic tool could be risky, especially since the remote evaluation of a picture for a rural patient could easily be misinterpreted. Depending on the gravity of the lesion, microscopy and biopsy could be employed to support diagnoses formulated by merely image observation.

Within a rural setting, this review revealed two studies that reported a reduction in the initial waiting period, one study that described an increased duration of rural teleconsultations, and one investigation that stated mitigation in travel distance and time. Telemedicine (within the context of teledermatology) has the potential to both significantly limit the need for rural patients to travel and deliver equitable treatment. ${ }^{73}$ Limited traveling and waiting periods have appeared to be practical features that could amplify appeal for the technology among patients. More importantly, it could be deduced that restricting travel for rural patients could maintain rural economic productivity since rural workers would not have to miss a day's work-mainly to have a minor dermatological lesion examined.

Within rural settings, one study reported limited biopsy complication rates and another one indicated a reliable identification of dermatological malignancies, two investigations revealed the ability of telereferrals to limit the time duration to biopsy, and one study demonstrated the importance of a follow-up protocol in refining diagnoses. This review could not find additional, similar studies conducted in this field. It was suggested that if there was a decreased time to biopsy with the telesystem (as noted in one study), this benefit could be attributed to the triaging technique embedded within that system. It could also be inferred that the follow-up of a telemodel has been vital in maintaining and ensuring the quality of care and patient safety. The drawbacks of a followup protocol could entail the extensive time necessary to do the follow-up, along with extra personnel to conduct the protocol.

Concerning patient and physician satisfaction in a rural setting, results of this review have such a clear and practical view of patients and physicians toward teledermatology. This positive perception could foster the expansion of existing teleservices and educational programs to improve access. Moreover, it could be assumed that patient satisfaction has been indicative of an enhanced health-related quality of life, thereby empowering informed patients to play an active role in consultation visits. By extension, the technology could facilitate patient socialization functioning, which could further augment positive patient health state. Patient satisfaction could be related to receiving timely information, personalized, holistic care, and decreased waiting periods. From the results of this review, it could be inferred that physicians have also viewed teleservices as an educational tool, in addition to merely a practical clinical tool.

In this review, two studies conducted in rural settings demonstrated cost-effectiveness. This cost-saving feature could be an economic incentive for patients and the health care system. It could be suggested that as the price of the teleequipment decreases with advances in technology, teledermatology could prove to be economically feasible. This review posits that the incentive to employ the technology could be enhanced if equivalent efficacy was obtained with the teleservice (at lower costs) as with conventional care.

There have been several advantages of teledermatology. It has permitted for the second opinion by worldwide dermatological experts on challenging cases. ${ }^{74}$ Virtual follow-up of chronic dermatological cases has been useful, and the transmission of images and clinical data through a mobile network 


\section{COUSTASSE ET AL.}

could be conducted in areas of fluctuating internet availability; moreover, technological services have provided online atlases, databases, and continuing medical education through the internet, thereby providing a user-friendly platform. ${ }^{75}$ Given the nationwide dermatologist shortage, the technology could be beneficial in improving access to individuals who could increasingly obtain health insurance under the Affordable Care Act mandate. ${ }^{76}$ Teledermatology has been helpful in triaging patients with dermatological lesions, ${ }^{77}$ especially in rural settings, ${ }^{78}$ and in triaging inpatient dermatological consultations as well. ${ }^{79}$ Moreover, mobile teledermatology has also been equally useful as a triaging tool. ${ }^{80}$ An overall benefit has been that teledermatology could enable clinical collaborations between dermatologists and primary care providers, thereby also allowing professionals from several clinical specialties to consult one another. ${ }^{81}$

There have also been several ensuing drawbacks of teledermatology, which included the following: clinical inadequacies (e.g., erroneous diagnoses, learning curve, and absence of face-to-face examinations); ethical quandaries (e.g., technological-oriented care as opposed to patient-oriented care and reduced personal doctor-patient relationships); reimbursement schemes; legal issues (e.g., legal framework that has lagged behind scientific advancements and physician responsibility for accurate diagnoses when employing such technology); and integration hurdles with electronic medical records have all continued to hamper the full potential of teledermatology. ${ }^{82}$ Photographic images could miss dermatopathological lesions, and these images alone have not been able to comprehensively address patient reservations and concerns. ${ }^{83}$ Issues with mobile teledermatology have included lack of image details (because of JPEG compression to enhance transmission) and the closeness of the flash device to the camera lens on the mobile device, which has not allowed for clarification of surface details. ${ }^{84}$ Some teleprograms have curbed expenses for patients, but not for the health care system, whereas other programs have enhanced quality, but not cost-efficiency. ${ }^{85}$ Physicians have utilized personal smartphones to exchange clinical data and images; since these devices have been subject to security breaches, the fear of violating patient confidentiality and the ensuing legal ramifications for physicians have been a concern. ${ }^{86}$

Limitations of this analysis could be ascribed to several restrictions employed in the literature search strategy. Also, it was not conducted funnel and/or forest plot to assess bias as it was out of the scope of this review. Finally, publication and researcher bias could not be ruled out.

There are some practical implications of teledermatology. Opponents have argued that a gradual deterioration in empa- thetic physician-patient relationships is a grave issue, since the technology can "dehumanize" this relationship; however, the technology can educate patients to ask focused questions about their problems, thereby maintaining and even solidifying the relationship. The successful utilization of the teleservice ultimately depends on the attitude of the physician; moreover, physician workload, and the payment system (capitated system vs. fee-for-service) play significant roles in adopting the service.

Moreover, investments in this form of technology in undeveloped and developing nations must be encouraged, so that practitioners can be persuaded to conduct research to seek for alternative technological modalities in the aim to reduce expenses for patients. Endeavors to amplify dermatological services to rural areas in developing nations will significantly depend upon collaborations between rural dermatological clinics and urban-based academic centers, along with an allocation of resources that depends upon population density. It is also imperative for policymakers to acknowledge the capability of the technology in enhancing access, and to formulate regulations through which the service can prudently assist routine dermatological care. Further research is needed, in particular, a formal meta-analysis study to have a more precise measurement of the effects of the teledermatological intervention in rural areas as well as appropriate metrics of variability.

\section{Conclusion}

Teledermatology has had a beneficial impact in improving dermatological access to rural areas. The success of this technology is contingent upon the commitment and willingness of the dermatologist in utilizing it.

\section{Disclosure Statement}

No competing financial interests exist.

\section{REFERENCES}

1. Kanthraj GR, Srinivas CR. Store and forward teledermatology. Indian J Dermatol Venereol Leprol 2007;73:5-12.

2. Romero G, Garrido JA, Garcla-Arpa M. Telemedicine and teledermatology (I): Concepts and applications. Actas Dermosifiliogr 2008;99:506-522.

3. Şenel E, Demir E. A global productivity and bibliometric analysis of telemedicine and teledermatology publication trends during 1980-2013. Dermatologica Sinica 2015;33:16-20.

4. Eminović N, de Keizer NF, Bindels PJE, Hasman A. Maturity of teledermatology evaluation research: A systematic literature review. Br J Dermatol 2007;156: 412-419.

5. Lee JJ, English JC. Teledermatology: A review and update. Am J Clin Dermatol 2018;19:253-260.

6. Morton CA, Downie F, Auld S, Smith B, van der Pol M, Baughn P, et al. Community photo-triage for skin cancer referrals: An aid to service delivery. Clin Exp Dermatol 2010;36:248-254.

7. Gaffney R, Rao B. Global teledermatology. Global Dermatol 2015;2:209-214. 
8. Weinberg J, Kaddu S, Gabler G, Kovarik C. The African teledermatology project: Providing access to dermatologic care and education in sub-Saharan Africa. Pan Afr Med J 2009;3:1-12.

9. Coates $S$, Kvedar J, Granstein R. Teledermatology: From a historical perspective to emerging techniques of the modern era. J Am Acad Dermato/ 2015;72:563-574.

10. Şenel E. History of teledermatology: A technique of the future in dermatology. Skinmed 2010;8:167-170.

11. United Nations. World urbanization prospects: The 2014 revision, highlights. Department of Economic and Social Affairs, Population Division. Available at https://esa.un.org/unpd/wup/publications/files/wup2014-highlights.pdf (last accessed August 21, 2017)

12. Korolenko W, Stepanenko VI. Teledermatology: First steps in ukraine in the light of contemporary world achievements. J Pigmentary Disord 2014;1:1-4.

13. US Census Bureau. "Urban and Rural." 2018. Available at www.census.gov/geo/ reference/urban-rural.html (last accessed November 2, 2018).

14. Levin YS, Warshaw EM. Teledermatology: A review of reliability and accuracy of diagnosis and management. Dermatol Clin 2009;27:163-176.

15. Eminović N, Dijkgraaf MG, Berghout RM, Prins AH, Bindels PJE, de Keizer NF. A cost minimization analysis in teledermatology: A model-based approach. $B M C$ Health Serv Res 2010;10:251.

16. Bashshur RL, Shannon GW, Tejasvi T, Kvedar JC, Gates M. The empirical foundations of teledermatology: A review of the research evidence. Telemedicine E Health 2015;21:953-979.

17. Kroemer S, Frühauf J, Campbell TM, Massone C, Schwantzer G, Soyer HP, et al. Mobile teledermatology for skin tumor screening: Diagnostic accuracy of clinical and dermoscopic image tele-evaluation using cellular phones. $\mathrm{Br} \mathrm{J}$ Dermatol 2011;164:973-979.

18. Elmslie $\mathrm{P}$, Elton H. The implementation of teledermatology in Australia. 2011. Australian Government Department of Health. Available at www.health.gov.aul internet/mbsonline/publishing.nsf/Content/DD0F66183EDF57C6CA257CD 20004A3A1/\$File/CHSWTFsub-TeleDerm.pdf (last accessed August 21, 2017).

19. Finch TL, Mair FS, May CR. Teledermatology in the U.K.: Lessons in service innovation. Br J Dermatol 2007;156:521-527.

20. Bobbs $M$, Bayer $M$, Frazer $T$, Humphrey $S$, Wilson $B$, Olasz $E$, et al. Building a global teledermatology collaboration. Int J Dermatol 2016;55:446-449.

21. Lamel S, Chambers CJ, Ratnarathorn M, Armstrong AW. Impact of live interactive teledermatology on diagnosis, disease management, and clinical outcomes. Arch Dermatol 2012;148:61-65.

22. Kaddu S, Soyer HP, Gabler G, Kovarik C. The Africa Teledermatology Project: Preliminary experience with a sub-Saharan teledermatology and e-learning program. J Am Acad Dermatol 2009;61:155-156.

23. Yao W, Chu CH, Li Z. The use of RFID in healthcare: Benefits and barriers. Proceedings of the 2010 IEEE International Conference on RFID Technology and Applications (RFID-TA). Piscataway, NJ. 2010;128-134.

24. McSweeney S, Pritt J, Swearingen, A. Kimble C, Coustasse A. Tele stroke: overcoming barriers to lifesaving treatment in rural hospitals. Perspectives in Health Information Management 2017;1-18.

25. Deslich S, Coustasse A. Expanding technology in the ICU: The case for the utilization of telemedicine. Telemed J E Health 2014;20:485-492.

26. Coustasse A, Meadows P, Hall RS 3rd, Hibner T, Deslich S. Utilizing radiofrequency identification technology to improve safety and management of blood bank supply chains. Telemed J E Health 2015;21:938-945.

27. Moher D, Liberati A, Tetzlaff J, Altman DG. The PRISMA Group. Preferred reporting items for systematic reviews and meta-analyses: The PRISMA statement. PLoS Med 2009;6:e1000097.

28. Kozera EK, Yang A, Murrell D. Patient and practitioner satisfaction with teledermatology including Australia's indigenous population: A systematic review of the literature. Int J Womens Dermatol 2016;2:70-73.

29. Cutler L, Ross K, Chiu M, Cutler D. Teledermatology: A model of feasibility in rural Haiti. J Am Acad Dermatol 2016;74:AB113.
30. Chen TS, Goldyne ME, Mathes EFD, Frieden IJ, Gilliam AE. Pediatric teledermatology: Observations based on 429 consults. J Am Acad Dermatol 2010;62:61-66

31. Thind CK, Brooker I, Ormerod AD. Teledermatology: A tool for remote supervision of a general practitioner with special interest in dermatology. Clin Exp Dermatol 2011;36:489-494.

32. Rubegni P, Nami N, Cevenini G, Poggiali S, Hofmann-Wellenhof R, Massone $C_{\text {, }}$ Bilenchi $R$, et al. Geriatric teledermatology: Store-and-forward vs. face-to-face examination. J Eur Acad Dermatol Venereol 2011;25:1334-1339.

33. Gatica JL, Bertoló S, Morales E, Espinoza M, Contreras C. Store-and-forward teledermatology in Chile: A contribution to primary health care. Piel Formación Continuada Dermatol 2015;30:148-154.

34. Carpio VM, Dofitas BL, Maaño CL, Dayrit CAF, Villena JA, Jara MFA, et al. Store-andforward teledermatology using mobile phones: Clinical Efficacy in a Rural Primary Healthcare Centre Free Clinic Setting. J Int Soc Telemed E Health 2016;4:1-8.

35. Saleh N, Abdel Hay R, Hegazy R, Hussein M, Gomaa D. Can teledermatology be a useful diagnostic tool in a dermatology practice in remote areas? An Egyptian experience with 600 patients. J Telemed Telecare 2017;23:233-238.

36. Nelson CA, Takeshita J, Wanat KA, Bream KDW, Holmes JH, Koenig HC, et al. Impact of store-and-forward (SAF) teledermatology on outpatient dermatologic care: A prospective study in an underserved urban primary care setting. J Am Acad Dermatol 2016;74:484-490.

37. Byrom L, Lucas L, Sheedy V, Madison K, Mclver L, Castrisos G, et al. Tele Derm National: A decade of teledermatology in rural and remote Australia. Aust $J$ Rural Health 2016;24:193-199.

38. Tran K, Ayad M, Weinberg J, Cherng A, Chowdhury M, Monir S, et al. Mobile teledermatology in the developing world: Implications of a feasibility study on 30 Egyptian patients with common skin diseases. J Am Acad Dermatol 2011; 64:302-309.

39. Muir J, Xu C, Paul S, Staib A, McNeil I, Singh P, et al. Incorporating teledermatology into emergency medicine. Emerg Med Australas 2011;23:562-568.

40. Garcia-Romero MT, Prado F, Dominguez-Cherit J, Hojyo-Tomomka MT, Arenas R. Teledermatology via a Social Networking Web Site: A Pilot Study between a General Hospital and Rural Clinic. Telemed E Health 2011;17:652-655.

41. Tsang MW, Kovarik CL. The role of dermatopathology in conjunction with teledermatology in resource-limited settings: Lessons from the African Teledermatology Project. Int J Dermatol 2011;50:150-156.

42. Warshaw EM, Hillman YJ, Greer NL, Hagel EM, MacDonald R, Rutks IR, et al. Teledermatology for diagnosis and management of skin conditions: $\mathrm{A}$ systematic review. J Am Acad Dermatol 2011;64:759-772.

43. Edison KE, Ward DS, Dyer JA, Lane W, Chance L, Hicks LL. Diagnosis, diagnostic confidence, and management concordance in live-interactive and store-andforward teledermatology compared to in-person examination. Telemed $E$ Health 2008;14:889-895.

44. Landow SM, Oh DH, Weinstock MA. Teledermatology within the veteran's health administration, 2002-2014. Telemed E Health 2015;21:769-773.

45. Desai B, McKoy K, Kovarik C. Overview of international teledermatology. Pan Afr Med J 2010;6:1-14.

46. Shrestha DP, Suwash B, Gurung D, Uprety A, Bhattarai S, Rosdahl I. Mobile teledermatology for rural Nepal: Dermatology care using a mobile phone in a primary health care center. J Inst Med 2016;38:7-10.

47. Byamba K, Syed-Abdul S, Garcla-Romero M, Huang CW, Nergyi S, Nyamdorj A, et al. Mobile teledermatology for a prompter and more efficient dermatological care in rural Mongolia. Br J Dermatol 2015;173:265-267.

48. Moreno-Ramırez D, Ferrándiz L, Nieto-Garcla A, Carrasco R, Moreno-Álvarez P, Galdeano $R$, et al. Store-and-forward teledermatology in skin cancer triage: Experience and evaluation of 2009 teleconsultations. Arch Dermatol 2007; 143:479-484.

49. Finnane $A$, Dallest $K$, Janda M, Soyer HP. Teledermatology for the diagnosis and management of skin cancer: A systematic review. JAMA Dermatol 2017;153: 319-327. 


\section{COUSTASSE ET AL.}

50. Wootton $\mathrm{R}$, Bahaadinbeigy $\mathrm{K}$, Hailey $\mathrm{D}$. Estimating travel reduction associated with the use of telemedicine by patients and healthcare professionals: Proposal for quantitative synthesis in a systematic review. BMC Health Serv Res 2011; $11: 1-10$

51. Vedire K, Joselow AL, Markham CM, Raugi GJ. Teledermatology-directed surgical care is safe and reduces travel. J Telemed Telecare 2015;22:121-126.

52. Karavan M, Compton N, Knezevich S, Raugi G, Kodama S, Taylor L, et al. Teledermatology in the diagnosis of melanoma. J Telemed Telecare 2014;20:18-23.

53. Hsiao JL, Oh DH. The impact of store-and-forward teledermatology on skin cancer diagnosis and treatment. J Am Acad Dermatol 2008;59:260-267.

54. Kahn E, Sossong S, Goh A, Carpenter D, Goldstein S. Evaluation of skin cancer in Northern California Kaiser Permanente's store-and-forward teledermatology referral program. Telemed E Health 2013;19:780-785.

55. Eastman KL, Lutton MC, Raugi GJ, Sakamoto MR, McDowell JA, McFarland LV, Reiber GE. A teledermatology care management protocol for tracking completion of teledermatology recommendations. J Telemed Telecare 2012;18:374-378.

56. McFarland LV, Raugi GJ, Reiber GE. Primary care provider and imaging technician satisfaction with a Teledermatology Project in Rural Veterans Health Administration Clinics. Telemed E Health 2013;19:815-825.

57. Vallejos OM, Quandt SA, Feldman SR, Fleischer AB, Brooks T, Cabral G, et al. Teledermatology Consultations Provide Specialty Care for Farmworkers in Rural Clinics. J Rural Health 2009;25:198-202.

58. McFarland LV, Raugi GJ, Taylor LL, Reiber GE. Implementation of an education and skills programme in a teledermatology project for rural veterans. J Telemed Telecare 2012;18:66-71.

59. Biscak TM, Eley R, Manoharan S, Sinnott M, Soyer HP. Audit of a State-wide store and forward teledermatology service in Australia. J Telemed Telecare 2013;19:362-366.

60. Assis TGP, Palhares DMF, Alkmim MBM, Marcolino MS. Teledermatology for primary care in remote areas in Brazil. J Telemed Telecare 2013;19:494-495.

61. Al Quran HA, Khader YS, Ellauzi ZM, Shdaifat A. Effect of real-time teledermatology on diagnosis, treatment, and clinical improvement. J Telemed Telecare 2015;21:93-99.

62. Hsueh MT, Eastman K, McFarland LV, Raugi GJ, Reiber GE. Teledermatology patient satisfaction in the Pacific Northwest. Telemed E Health 2012;18:377-381.

63. Ferrándiz L, Moreno-Ramırez D, Ruiz-de-Casas A, Nieto-Garcla A, MorenoÁlvarez $\mathrm{P}$, Galdeano $\mathrm{R}$, et al. An economic analysis of presurgical teledermatology in patients with nonmelanoma skin cancer. Actas Dermosifiliográficas 2008;99:795-802.

64. Moreno-Ramırez D, Ferrándiz L, Ruiz-de-Casas A, Nieto-Garcla A, Moreno-Álvarez $P$, Galdeano R, et al. Economic evaluation of a store-and-forward teledermatology system for skin cancer patients. J Telemed Telecare 2009;15:40-45.

65. Pak HS, Datta SK, Triplett CA, Lindquist JH, Grambow SC, Whited JD. Cost minimization analysis of a store-and-forward teledermatology consult system. Telemed E Health 2009;15:160-165.

66. Henning JS, Wohltmann W, Hivnor C. Teledermatology from a Combat Zone. Arch Dermatol 2010;146:676-677.

67. Whited JD. Economic analysis of telemedicine and the teledermatology paradigm. Telemed E Health 2010;16:223-228.

68. Van der Heijden JP, de Keizer NF, Bos JD, Spuls PI, Witkamp L. Teledermatology applied following patient selection by general practitioners in daily practice improves efficiency and quality of care at lower cost. Br J Dermatol 2011;165:1058-1065.

69. Lim D, Oakley AMM, Rademaker M. Better, sooner, more convenient: A successful teledermoscopy service. Australas J Dermatol 2012;53:22-25.

70. Livingstone J, Solomon J. An assessment of the cost-effectiveness, the safety of referral and patient satisfaction of a general practice teledermatology service. London J Prim Care 2015;7:31-35.

71. Snoswell C, Finnane A, Janda M, Soyer HP, Whitty JA. Cost-effectiveness of store-and-forward teledermatology: A systematic review. JAMA Dermatol 2016;152:702-708.
72. Datta SK, Warshaw EM, Edison KE, Kapur K, Thottapurathu L, Moritz TE, et al. Cost and utility analysis of a store-and-forward teledermatology referral system: A randomized control trial. JAMA Dermatol 2015;151:1323-1329.

73. Armstrong AW, Dorer DJ, Lugn NE, Kvedar JC. Economic evaluation of interactive teledermatology compared with conventional care. Telemed $E$ Health 2007;13:92-100.

74. Greisman L, Nguyen TM, Mann RE, Baganizi M, Jacobson M, Paccione GA, Friedman $\mathrm{AJ}$, et al. Feasibility and cost of a medical student proxy-based mobile teledermatology consult service with Kisoro, Uganda, and Lake Atitlan, Guatemala. Int J Dermatol 2014;54:685-692.

75. Hanada E, Ikebuchi K, Miyamoto M, Kitani M, Yamaguchi S, Dekio I, Morita E. (2009). An Interactive Medical Support System for Dermatology in Rural Areas. In World Congress on Medical Physics and Biomedical Engineering, Munich, Germany, 2009.

76. Dekio I, Hanada E, Chinuki Y, Akaki T, Kitani M, Shiraishi Y, Kaneko S, Furumara M, Morita E. Usefulness and economic evaluation of ADSL-based live interactive teledermatology in areas with a shortage of dermatologists. Int J Dermatol 2010;49:1272-1275.

77. Shannon GW, Buker CM. Determining accessibility to dermatologists and teledermatology locations in Kentucky: Demonstration of an innovative geographic information systems approach. Telemed E Health 2010;16:670-677.

78. Hayashida K, Fujioka M, Senju C. Teledermatology may play a role in reducing severity of pressure ulcers in both rural and urban settings. Wounds $2014 ; 26$ : 83-88.

79. Sáenz JP, Novoa MP, Correal D, Eapen BR. Skin health, a mobile application for supporting Teledermatology: A case study in a rural area in Columbia. 6th EAI International Conference on Wireless Mobile Communication and Healthcare Milan, Italy: MobiHealth, November 14-16, 2016;160-163.

80. Johnson MN, Armstrong AW. Technologies in dermatology: Teledermatology review. G Ital Dermatol Venereol 2011;146:143-153.

81. Armstrong AW, Wu J, Kovarik CL, Goldyne ME, Oh DH, McKoy KC, et al. State of teledermatology programs in the United States. J Am Acad Dermatol 2012;67: 939-944.

82. McCourt C, Dolan 0, Gormley G. Malignant melanoma: A pictorial review. Ulster Med J 2014;83:103-110.

83. Falk $M$, Anderson $C$. Reliability of self-assessed reading of skin tests: A possible approach in research and clinical practice? Dermatol Online J 2010;16:4.

84. Moffatt JJ, Eley DS. The reported benefits of telehealth for rural Australians. Aust Health Rev 2010;34:276-281.

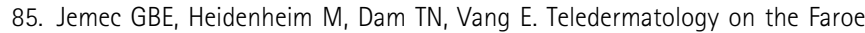
Islands. Int J Dermatol 2008;47:891-893.

86. Warshaw EM, Lederle FA, Grill JP, Gravely AA, Bangerter AK, Fortier LA, et al. Accuracy of teledermatology for pigmented neoplasms. J Am Acad Dermatol 2009;61:753-765.

Address correspondence to: Alberto Coustasse, DrPH, MD, MBA, MPH Healthcare Administration Program Lewis College of Business Marshall University South Charleston, WV 25303

E-mail: coustassehen@marshall.edu

Received: May 8, 2018

Revised: November 16, 2018

Accepted: November 19, 2018

Online Publication Date: February 11, 2019 